\title{
Article \\ Clinical Application of the Novel Cell-Based Biosensor for the Ultra-Rapid Detection of the SARS-CoV-2 S1 Spike Protein Antigen: A Practical Approach
}

\author{
Sophie Mavrikou ${ }^{1, *} \mathbb{D}^{\circ}$, Vasileios Tsekouras ${ }^{1}\left(\mathbb{D}\right.$, Kyriaki Hatziagapiou $\left.^{2,3}{ }^{(}\right)$, Foteini Paradeisi ${ }^{1}$, Petros Bakakos ${ }^{4}$, \\ Athanasios Michos ${ }^{2}{ }^{-1}$, Antonia Koutsoukou ${ }^{4}$, Elissavet Konstantellou ${ }^{4}$, George I. Lambrou ${ }^{2} \mathbb{D}$, Eleni Koniari ${ }^{5}$,

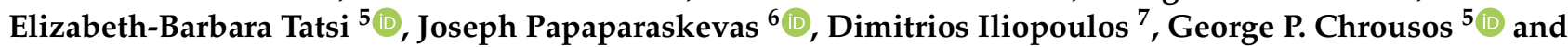 \\ Spyridon Kintzios $1, *(1)$
}

check for updates

Citation: Mavrikou, S.; Tsekouras, V.; Hatziagapiou, K.; Paradeisi, F.; Bakakos, P.; Michos, A.; Koutsoukou, A.; Konstantellou, E.; Lambrou, G.I.; Koniari, E.; et al. Clinical Application of the Novel Cell-Based Biosensor for the Ultra-Rapid Detection of the SARS-CoV-2 S1 Spike Protein Antigen: A Practical Approach. Biosensors 2021, 11, 224. https:// doi.org/10.3390/bios11070224

Received: 1 June 2021

Accepted: 3 July 2021

Published: 6 July 2021

Publisher's Note: MDPI stays neutral with regard to jurisdictional claims in published maps and institutional affiliations.

Copyright: (c) 2021 by the authors. Licensee MDPI, Basel, Switzerland. This article is an open access article distributed under the terms and conditions of the Creative Commons Attribution (CC BY) license (https:/ / creativecommons.org/licenses/by/ $4.0 /)$.
1 Laboratory of Cell Technology, Department of Biotechnology, Agricultural University of Athens, EU-CONEXUS European University, 11855 Athens, Greece; tsekouras@aua.gr (V.T.); stud315079@aua.gr (F.P.)

2 First Department of Pediatrics, National and Kapodistrian University of Athens, "Aghia Sophia" Children's Hospital, Thivon 1, 11527 Athens, Greece; khatziag@med.uoa.gr (K.H.); amichos@med.uoa.gr (A.M.); glamprou@med.uoa.gr (G.I.L.)

3 Physiotherapy Department and Department of Nursing, Faculty of Health and Care Sciences, State University of West Attica, Agiou Spiridonos 28, 12243 Egaleo, Athens, Greece

4 First University Department of Respiratory Medicine, "Sotiria" Hospital, Medical School, National and Kapodistrian University of Athens, 152 Mesogeion Ave, 11527 Athens, Greece; pbakakos@med.uoa.gr (P.B.); akoutsou@med.uoa.gr (A.K.); eliskonst@yahoo.gr (E.K.)

5 University Research Institute of Maternal and Child Health and Precision Medicine, and UNESCO Chair on Adolescent Health Care, National and Kapodistrian University of Athens, "Aghia Sophia" Children's Hospital, Thivon \& Livadias 8 str, 11527 Athens, Greece; eltheo1983@gmail.com (E.K.); etatsi@med.uoa.gr (E.-B.T.); chrousos@gmail.com (G.P.C.)

6 Department of Microbiology, Medical School, National and Kapodistrian University of Athens, Mikras Asias 75, 11527 Athens, Greece; ipapapar@med.uoa.gr

7 Emergency Operations Center, National Public Health Organization (NPHO), Agrafon 3-5, 15123 Athens, Greece; d.iliopoulos@eody.gov.gr

* Correspondence: sophie_mav@aua.gr (S.M.); skin@aua.gr (S.K.)

Abstract: The availability of antigen tests for SARS-CoV-2 represents a major step for the mass surveillance of the incidence of infection, especially regarding COVID-19 asymptomatic and/or early-stage patients. Recently, we reported the development of a Bioelectric Recognition Assay-based biosensor able to detect the SARS-CoV-2 S1 spike protein expressed on the surface of the virus in just three minutes, with high sensitivity and selectivity. The working principle was established by measuring the change of the electric potential of membrane-engineered mammalian cells bearing the human chimeric spike S1 antibody after attachment of the respective viral protein. In the present study, we applied the novel biosensor to patient-derived nasopharyngeal samples in a clinical set-up, with absolutely no sample pretreatment. More importantly, membrane-engineered cells were preimmobilized in a proprietary biomatrix, thus enabling their long-term preservation prior to use as well as significantly increasing their ease-of-handle as test consumables. The plug-and-apply novel biosensor was able to detect the virus in positive samples with a $92.8 \%$ success rate compared to RTPCR. No false negative results were recorded. These findings demonstrate the potential applicability of the biosensor for the early, routine mass screening of SARS-CoV-2 on a scale not yet realized.

Keywords: Bioelectric Recognition Assay (BERA); membrane engineering; public health surveillance; Point-of-Care (POC); S1 spike protein; rapid antigen test; screening; serological assay; severe acute respiratory syndrome-coronavirus 2 (SARS-CoV-2)

\section{Introduction}

Assays targeting antigenic moieties of the respiratory syndrome-coronavirus 2 (SARSCoV-2) have been recognized as one of the most promising approaches to successfully 
identify asymptomatic carriers of the virus, especially during the first two weeks following infection [1-3] and taking into consideration the fact that asymptomatic infection rates range globally between $18 \%$ and $42 \%$ [4]. In practical terms, screening for viral antigens differentiates itself from antibody-targeting serology tests since it does not depend on host antibody accumulation to detectable levels in the second and third week of illness [5]. The interest in screening individuals for COVID-19 infection in point-of-care (POC) settings is concomitant with the wide vaccination against the virus [6]. Although nucleic acid-based tests are considered the golden standard for SARS-CoV-2, they are prone to false-negative or even contradictory results, especially before or at symptom onset [7-9]. In the context of immunological assays, antigen-detecting methods are advantageous over serology-based ones, since no prior seroconversion (usually peaking around one to two weeks after the onset of symptoms) is required $[10,11]$. Among the four major surface protein types, spike proteins have a prominent role in the development of diagnostic assays, since they are directly involved in the mechanism of host cell entry through their ability to bind to the angiotensin-converting enzyme 2 (ACE2), in turn determining the level of infectiousness and virulence of the virus. More significantly, although the most abundant protein of the virus is the nucleocapsid one $(\mathrm{N})$, spike $(\mathrm{S})$ proteins, being the host attachment ones, are considered more specific [12].

Currently, the overwhelming majority of antigen rapid tests for SARS-CoV-2 are targeting the nucleocapsid protein, usually coupled with lateral flow assay configurations [13]. They are usually characterized by high (>90\%) specificity and clinical accuracy [14]; however, they suffer from poor sensitivity, at least compared to RT-PCR (Real-Time Polymerase Chain Reaction) [15]. For this reason, they are mainly used in symptomatic patients [16,17]. On the other hand, a more promising target for antigen assays is the S1 spike protein of SARS-CoV-2, since it is centrally involved in the early stages of infection and, thus, is the major antigen recognized by humoral and cellular immune responses as a mirror of the whole virus $[18,19]$, as well as a molecular tool to discriminate between different coronaviruses (e.g., SARS-CoV-2 vs. SARS-CoV) [20].

In spite of its attractiveness as a basis for the development of coronavirus antigen tests, extremely few reports are available on the sensitive and reliable detection of the SARS-CoV S1 protein [21-23]. Even more rare are reports on clinical validation and/or practical application of such approaches [24].

Our team has recently reported the proof-of-concept development of a novel biosensor for the ultra-rapid (3 min) and sensitive detection of the SARS-CoV-2 S1 spike protein [25], with a limit of detection of $1 \mathrm{fg} / \mathrm{mL}$ and a semilinear range of response between $10 \mathrm{fg}$ and $1 \mu \mathrm{g} / \mathrm{mL}$. The biosensor was based on mammalian cells, which were engineered by electroinserting the human chimeric spike S1 antibody. According to a well-established process known as Molecular Identification through Membrane Engineering [26-28], binding of the SARS-CoV-2 S1 protein to complementary membrane-based antibodies resulted in a considerable and selective change in the membrane-engineered cell bioelectric properties, which was measured with a customized portable read-out device operated via smartphone/tablet $[29,30]$. This is a broad methodology based on the electroinsertion of antibody molecules on the cell surface of mammalian cells. The attachment of a specific antigen to its respective antibody causes a measurable change in the cell membrane structure, leading to a change in the cell membrane potential. Moreover, membrane-engineered cells have been utilized as biorecognition elements in various sensors applied for the detection of human viruses such as Hepatitis B Virus [31], Hepatitis C Virus [29], SARS-CoV-2 [25,32], as well as several plant viruses such as Cucumber mosaic virus (CMV) [28], Potato virus $Y$ (PVY), and Tobacco rattle virus (TRV) [33]. Very recently, our system has been validated by another independent research team on 110 positive and 136 negative SARS-CoV-2 samples tested by RT-PCR [32]. A total sensitivity of $92.7 \%$ and a specificity of $97.8 \%$ was demonstrated. However, it should be emphasized that samples assayed with the biosensor were processed according to the specifications for molecular (RT-PCR) testing, i.e., the samples were considerably pretreated before testing. 
In the present study, we report on the first clinical application of an improved version of our novel biosensor, configured as ready-to-use. Positive patient-derived samples were identified with a $92.8 \%$ score compared to RT-PCR, while no false-negative results were recorded. We demonstrated that, following further validation, our approach could be applied for early and routine population testing for SARS-CoV-2 with minimal sample processing, easy use, and at a scale of application not realized so far.

\section{Materials and Methods}

\subsection{Cell Culture Conditions}

The SK-N-SH neuroblastoma cells (ATCC ${ }^{\circledR}$ HTB- $11^{\mathrm{TM}}$ ) were cultured under standard conditions $\left(37^{\circ} \mathrm{C}, 5 \% \mathrm{CO}_{2}\right)$, in $1 \times$ Minimum Essential Medium (MEM) with Earle's balanced salt (Biowest, Nuaillé, France). Fetal bovine serum (FBS) (10\%) (Thermo Fisher Scientific, Waltham, MA, USA) was added to the culture medium, as well as $2 \mathrm{mM}$ of l-glutamine, $0.1 \mathrm{mM}$ nonessential amino acids, $1.0 \mathrm{mM}$ sodium pyruvate (Biowest, Nuaillé, France) and $1 \mathrm{U} \mathrm{\mu g}^{-1}$ antibiotics (penicillin/streptomycin). Cells were subcultured once or twice per week in a 1:10 ratio. Trypsin-EDTA (0.05\% trypsin, 0.02\% EDTA) (Biowest, Nuaillé, France) was used for cell dissociation from the culture flasks, after treatment for 3-10 min.

\subsection{Sensor Fabrication from Membrane-Engineered Cells (SK-N-SH/Anti S1)}

Membrane engineered cells were fabricated after the electroinsertion of SARS-CoV2 Spike S1 antibody (Recombinant Anti-SARS-CoV-2 Spike Glycoprotein S1 antibody [CR3022] - Chimeric, Cambridge, United Kingdom) into the cell membrane, according to the prior publication of Mavrikou et al. [25]. The SK-N-SH cells were harvested from a culture vessel by trypsinization. Cells were resuspended in phosphate-buffered saline (PBS) (pH 7.4), at a final density of $2.5 \times 10^{6} / \mathrm{mL}$, alongside the antibody $(0.5 \mu \mathrm{g} / \mathrm{mL})$ and maintained at $4{ }^{\circ} \mathrm{C}$ for $20 \mathrm{~min}$. The cell suspension was then subjected to electroporation with two pulses of an electric field at $1800 \mathrm{~V} / \mathrm{cm}$ (Eppendorf Eporator, Eppendorf AG, Hamburg, Germany) and was immediately transferred in a Petri dish $(60 \times 15 \mathrm{~mm})$ enriched with cell culture medium and placed in the incubator overnight.

The next day, the membrane-engineered cells were detached from the petri dish with pipetting and collected with PBS (pH 7.4) in Eppendorf tubes in desirable concentrations. The interactions of membrane-engineered cells with the spike S1 protein were then recorded either in cell suspensions $\left(50 \times 10^{3}\right.$ cells per sensor) or in three-dimensional (3D) cell cultures ( $25 \times 10^{3}$ cells per sensor). In the case of $3 \mathrm{D}$ cultures, a custom-made extracellular collagen-based (at least $0.5 \% w / v$ ) hydrogel matrix was used for cell immobilization (the formulation is subjected to patent submission) (Figure 1). 


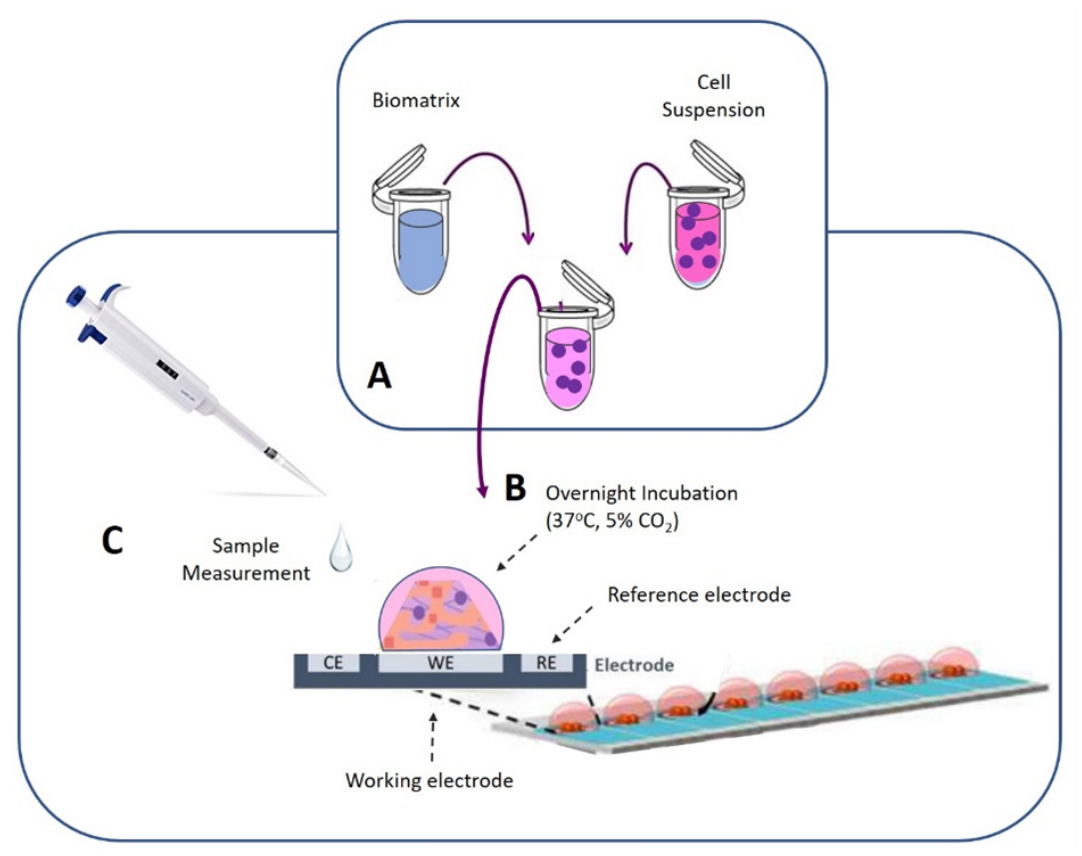

Figure 1. Cells were mixed with the hydrogel matrix (A) and were placed onto the working electrode's surface. The electrodes were put in petri dishes and were incubated overnight at $37^{\circ} \mathrm{C}, 5 \% \mathrm{CO}_{2}(\mathbf{B})$. The next day the modified electrodes with the 3D cultures were ready for use $(\mathbf{C})$.

\subsection{Bioelectric Real-Time Measurements: Biosensor Set-Up and Experimental Design}

It is well documented that the alterations of the membrane potential of membraneengineered cells due to the interactions between the electroinserted receptor molecules and analyte anions, cause the production of electric signals that can be recorded, according to the principle of the Bioelectric Recognition Assay (BERA) [29,30]. Our method of choice for measuring potential changes was the determination of Open Circuit Potential (OCP) values. OCP is the potential established between the working electrode and the environment, with respect to a reference electrode, which will be placed in the electrolyte close to the working electrode. OCP is a passive method, meaning that the counter electrode (necessary to pass current through the cell) circuitry of the potentiostat is bypassed. In this mode, only the resting potential between reference and working electrode is measured [34].

For this purpose, a customized potentiometer with an eight-channel configuration was used to record the membrane-engineered cells' electric properties. Carbon screen printed multichannel electrodes were used (working electrode: carbon, reference: $\mathrm{Ag} / \mathrm{AgCl}$ ) on a disposable sensor strip (iMiCROQ S.L., Tarragona, Spain) (Figure 2A,B).

Samples $(10 \mu \mathrm{L})$ were added to the top of each carbon electrode containing membrane engineered cells either in suspension or 3D culture by using a multichannel automatic pipette (Figure 2C). Upon the addition of the sample, a time series of cell responses was recorded for $180 \mathrm{~s}$ by potentiometric measurements in volts (360 values, sampling rate $2 \mathrm{~Hz}$ ). The recorded measurements were uploaded via a tablet/Bluetooth communication to a cloud server and further analyzed (Figure 2D) [35].

Each sample was tested eight times using a set of eight individual sensors and each experiment was performed in triplicate, while each experimental set was repeated at three different dates $(n=24)$. The biosensor measurements are expressed as normalized responses according to the following equation:

$$
\text { Normalized Biosensor Response }=\frac{\text { Control }- \text { Sample }}{\text { Control }}
$$

The results are expressed as mean $\pm \mathrm{SEM}$, whereas the differences between the means were tested for statistical significance using an analysis of variance and Student's $t$-test. 
The present study was carried out in three experimental steps. Initially, we investigated our system's lower limits of detection. For this purpose, we spiked SARS-CoV-2 negative patient nasopharyngeal samples with several low concentrations of SARS-CoV-2 spike S1 protein $(2 \mathrm{fg} / \mathrm{mL}, 20 \mathrm{fg} / \mathrm{mL}, 200 \mathrm{fg} / \mathrm{mL}, 2 \mathrm{pg} / \mathrm{mL}, 20 \mathrm{pg} / \mathrm{mL}, 200 \mathrm{pg} / \mathrm{mL}$, and $2 \mathrm{ng} / \mathrm{mL}$ ) to reflect the usual concentrations of viral protein ranging from asymptomatic to moderately ill patients in vivo. Then, we tested the spiked samples with the membrane engineered cells in suspension or in 3D culture.

In the second experimental step, we evaluated the BERA biosensor based on 3D membrane-engineered cell culture with SARS-CoV-2 negative and positive patient nasopharyngeal samples. Finally, in the third experimental step, cell viability in 3D cultures was assessed for long-term storage as part of the biosensors' consumable components.

A

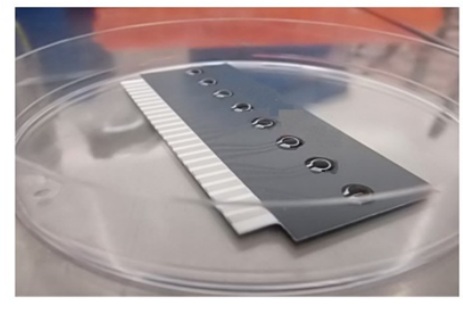

D

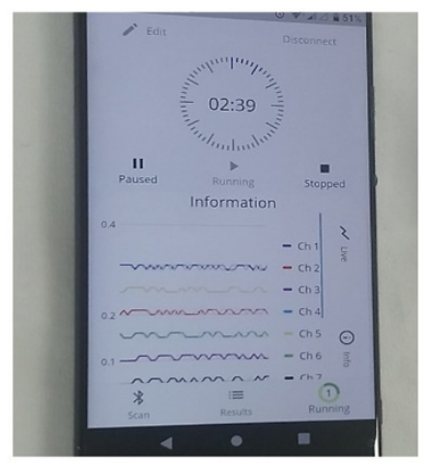

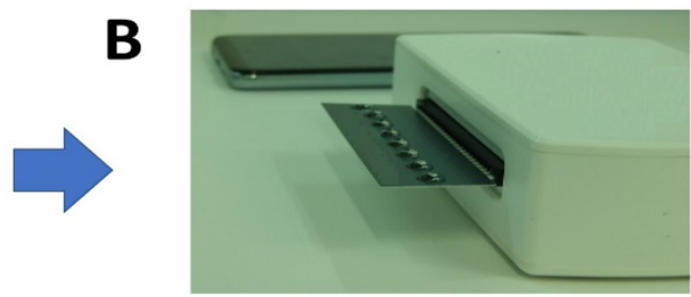

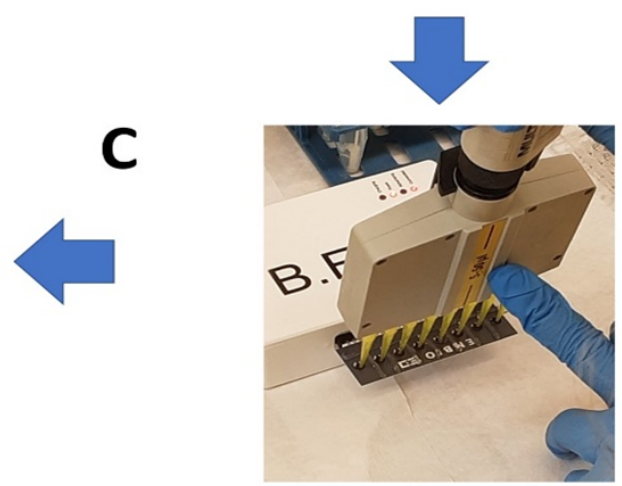

Figure 2. Experimental set-up of the membrane-engineered cell-based biosensor's assembly. Eightchannel carbon screen-printed electrodes were prepared with custom-made hydrogel-immobilized membrane-engineered cells (A). The electrode containing the 3D cell cultures was placed to the measurement device $(\mathbf{B})$. Each sample was applied $(8 \times)$ to the testing positions (cell-covered electrodes) while the electrode strip was connected to a bespoke portable potentiometer which is connected to a tablet device for the recording of the measurements immediately after the sample application (C). The electric signal is continuously visualized through a voltage vs. time graph on the screen of a smartphone connected via Bluetooth to the device (D).

\subsection{Viability Monitoring of Membrane-Engineered Cells in 3D Extracellular Immobilization Matrix}

To access the proliferation and viability of the cell membrane engineered with the SARS-CoV-2 Spike S1 antibody in the hydrogel immobilization matrix, we microscopically observed cell viability for two weeks within three days intervals. The Trypan Blue Exclusion Assay was performed in order to determine cell death [36]. Cell viability changes were captured (from Day $1=24 \mathrm{~h}$ after electroporation) by an inverted microscope (ZEISS Axio Vert.A1, Carl Zeiss Microscopy, LLC, White Plains, NY, USA), and the pictures were processed by ZEN lite and ImageJ software.

\subsection{Patient Recruitment, Clinical Examination and Specimen Collection}

All patients included in the study had a positive RT-PCR test on nasopharyngeal swabs for SARS-CoV-2 at the time of hospital admission and prior to sample collection for antigen detection with the biosensor. Overall, the severity of their disease was mild to moderate, except for one patient who was finally intubated. Nasopharyngeal swabs 
for antigen detection were collected, following a standardized procedure, using Dacron swabs (FIRATMED, 8870000244, Albacete, Spain). Fourteen patients and fourteen healthy volunteers consented to have two replicate specimens collected. Healthy volunteers had already received two doses of COVID-19 mRNA vaccine and were matched to patients. Matching parameters included sex, age, and medical history. All specimens for antigen testing were collected at 12 March 2021. Each specimen was transported in a sterile centrifuge tube (Greiner $15 \mathrm{~mL}$ centrifuge tube). For each patient or volunteer, the first swab was placed into $10 \mathrm{~mL}$ of sterile $0.9 \%$ saline solution and the second one into $10 \mathrm{~mL}$ of PBS at pH 7.4 (Gibco PBS, 10010023, Thermo Fisher Scientific, Waltham, MA, USA). Specimens were stored on ice for transport to the clinical laboratory for testing. Upon receipt, the specimens were stored at $-80^{\circ} \mathrm{C}$, until the process $[37,38]$.

The clinical characteristics of patients with COVID-19 as well as their medical history are described in Supplementary Table S1 of the supporting information.

\section{Results}

In a previous study, we demonstrated the proof-of-concept detection of the SARS-CoV2 spike S1 protein by means of a Bioelectric Recognition Assay recording the alterations of the cellular bioelectric properties of membrane-engineered mammalian cells bearing the human chimeric spike S1 antibody [25]. As a next step, in the present investigation we tried to evolve our technology: (i) using new cellular biorecognition elements to augment the biosensor's sensitivity, (ii) by the integration of the biorecognition elements into a collagen-like hydrogel for increasing storage time, and (iii) by the evaluation of the assay's performance with the use of clinical samples.

3.1. Membrane-Engineered SK-N-SH/Anti-S1 Cells Have a Distinct Response against the SARS-CoV-2 Spike S1 Protein in Suspension and 3D Culture Conditions

Membrane-engineered cells with $0.5 \mu \mathrm{g} / \mathrm{mL}$ human monoclonal anti-S1 antibodies were exposed to increasing concentrations ( $2 \mathrm{fg} / \mathrm{ML}-2 \mathrm{ng} / \mathrm{mL}$ ) of the SARS-CoV-2 spiked $S 1$ protein. A clearly observable and very rapid response was produced, measurable within 3 min of cell-protein interaction. The generated signal from the membrane-engineered cells cultured either in suspension (Figure 3) or in the 3D extracellular matrix (Figure 4) was clearly distinguishable.

A $10 \mu \mathrm{L}$ sample volume of various concentrations of the S1 protein was administered to a population of $25 \times 10^{3}$ membrane engineered cells. Measurements at each S1 protein concentration were distinctly and significantly different from the control solutions (i.e., zero $\mathrm{S} 1$ concentration). Results were quite reproducible, with a very low limit of detection (LOD) at two (2) $\mathrm{fg} / \mathrm{mL}$.

A concentration-dependent linear pattern was observed after the administration of increasing concentrations of the SARS-CoV-2 spike S1 protein, in the range of $2 \mathrm{fg}$ $20 \mathrm{pg} / \mathrm{mL}$. Additionally, the responses of the cells in 3D cultures as well as in suspension, upon the addition of the S1 protein solution, were similar. The 3D cultured cells produced more reproducible responses for each applied concentration of S1 protein, in comparison with the respective responses of the cell suspensions. This conclusion is based on the relative standard error comparison (RSE), since in all assayed concentrations that are equal or higher than $20 \mathrm{fg} / \mathrm{mL}$, the RSEs of the normalized 3D cultured cells' responses (average RSE: $\pm 9.4 \%$ ) were lower than those obtained from the cells in suspension (average RSE: $\pm 14.3 \%)$. 


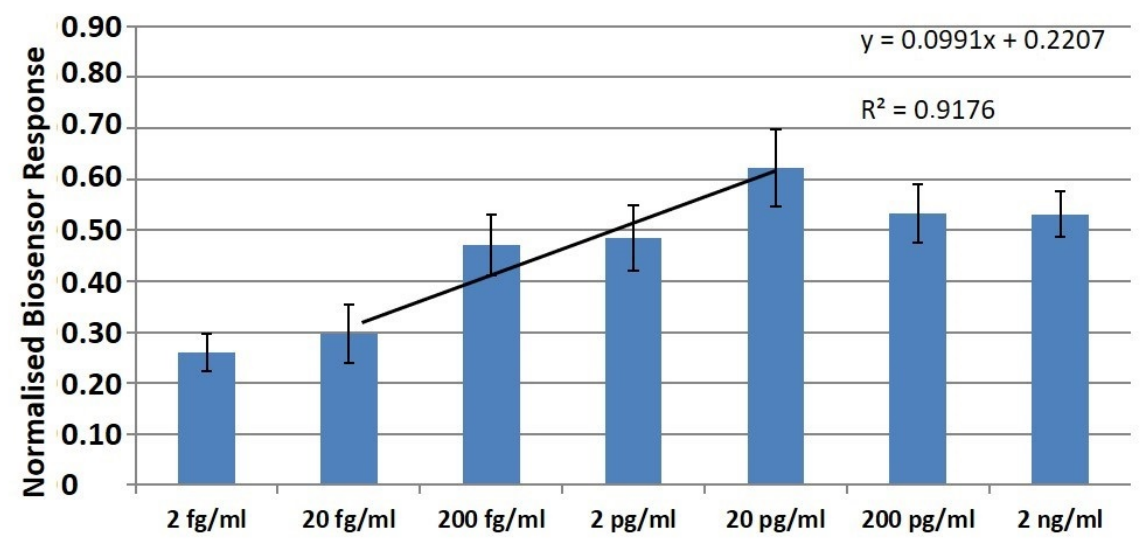

\section{S1 Concentration}

Figure 3. Normalized (vs. control) cell biosensor's responses in suspension against the SARSCoV-2 spike S1 protein. SK-N-SH/anti-S1 cells membrane-engineered with $0.5 \mu \mathrm{g} / \mathrm{mL}$ of human monoclonal antibodies were used as the biorecognition elements. Results (mean $\pm \mathrm{SE}$ ) are presented after three minutes (columns) of sample-cell interaction. Results are expressed as normalized biosensor responses ([control-sample response]/control, $n=24$ ).

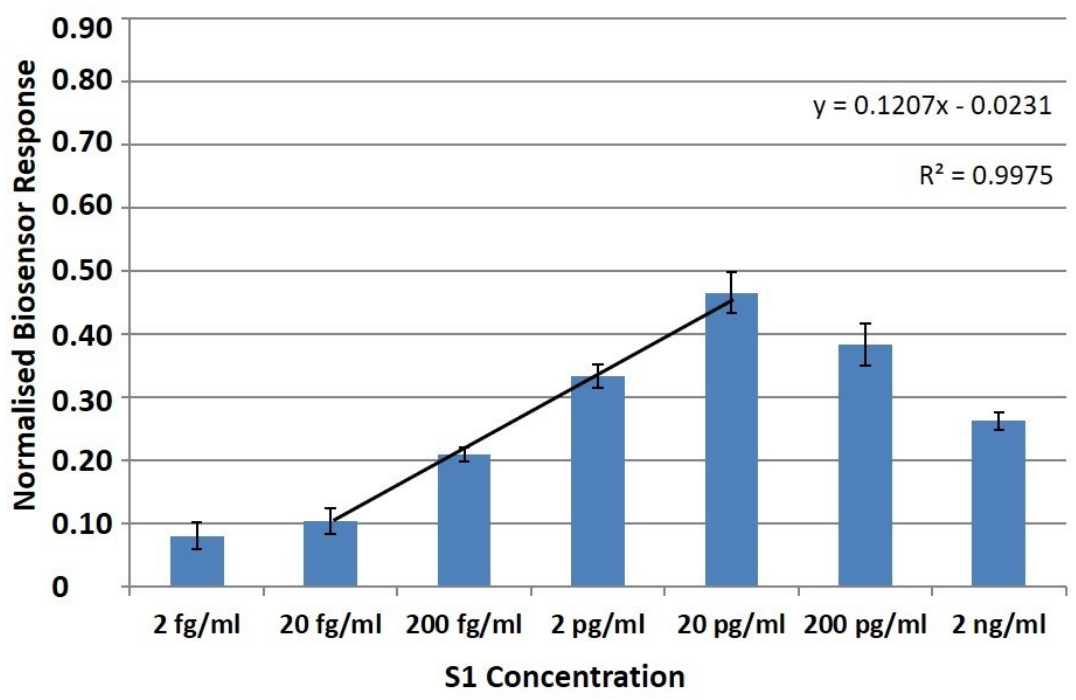

Figure 4. Normalized (vs. control) 3D immobilized cell biosensor's response to the SARS-CoV-2 spike S1 protein. SK-N-SH/anti-S1 cells membrane engineered with $0.5 \mu \mathrm{g} / \mathrm{mL}$ of human monoclonal antibodies, were used as the biorecognition element. Results are presented after three minutes (columns) of sample-cell interaction. Results are expressed as normalized biosensor responses ([control-sample response]/control, $n=24$ ).

3.2. Ultra-Rapid Detection of the SARS-CoV-2 S1 Spike Protein Antigen in Clinical Samples by the Membrane-Engineered SK-N-SH/Anti-S1 Cells in Suspension and 3D Conditions in Comparison with RT-PCR Results

Two different approaches were applied, based on membrane engineered cells in suspension and in 3D cultures. Comparison of the performances of suspension and 3D cultures to those of RT-PCR with samples from all categories of patients gave similar results regardless of the methodology used. In total, 14 (58.33\%) of the 24 samples were positive for SARS-CoV-2 virus. Our cell-based biosensor successfully detected the virus in 13 out of 14 specimens $(92.8 \%$ ) confirmed to be positive by RT-PCR. In addition, no false-positive results were observed in the case of negative samples $(n=10)$. 
As can be seen in Figure 5, the normalized cell biosensor's responses derived from membrane engineered cells in suspension successfully identified six specimens (42.8\%) with statistical significance $p<0.001$, three specimens $(21.4 \%)$ with statistical significance $p<0.01$ and four specimens (28.5\%) with statistical significance $p<0.05$. Non- statistically significant results were observed in the case of specimen 14 . When we used cells immobilized in a hydrogel-based extracellular matrix (Figure 6), the biosensor identified 12 specimens $(85.7 \%)$ with statistical significance $p<0.001$ and one specimen $(7.1 \%)$ with statistical significance $p<0.05$. In this case, non-statistically significant results were observed for specimen 5 .

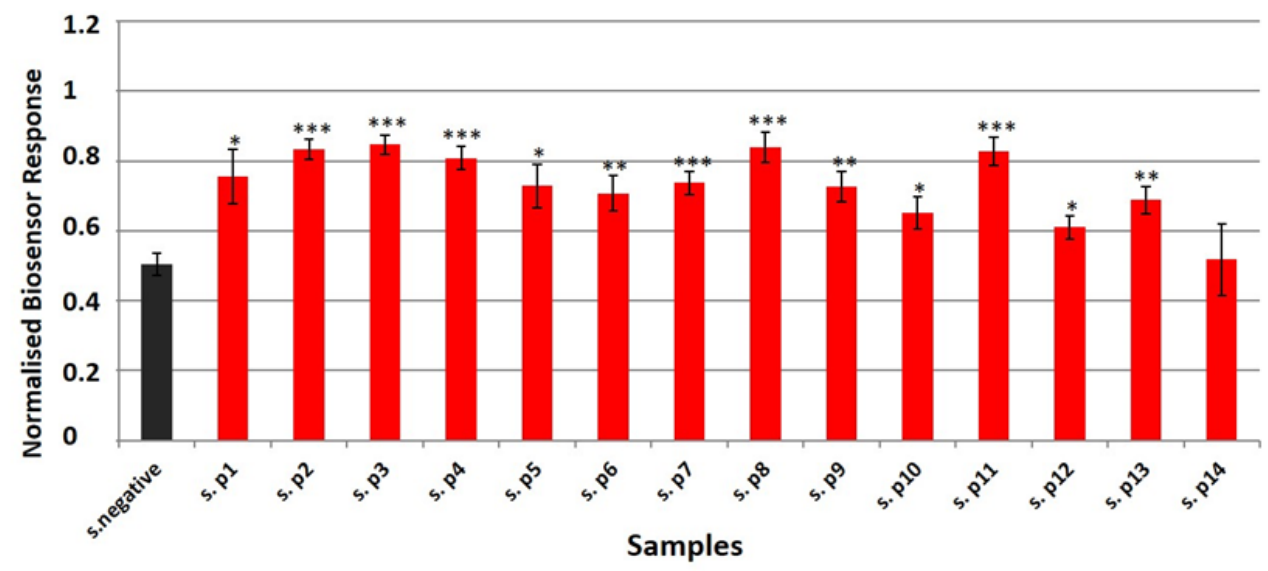

Figure 5. Normalized cell biosensor's responses to clinical samples from patients $(n=14)$ and healthy donors (mean of 10 samples-black column). The membrane engineered cells with the Anti-SARS-CoV-2 Spike S1 antibody were added onto the electrode's surface in suspension. Results are presented after three minutes of sample-cell interaction. Results are expressed as normalized biosensor responses ([control-sample response]/control). Significant differences (Student's T-test) between normalized biosensor responses ${ }^{*}<0.05,{ }^{* *}<0.01,{ }^{* * *}<0.001$.

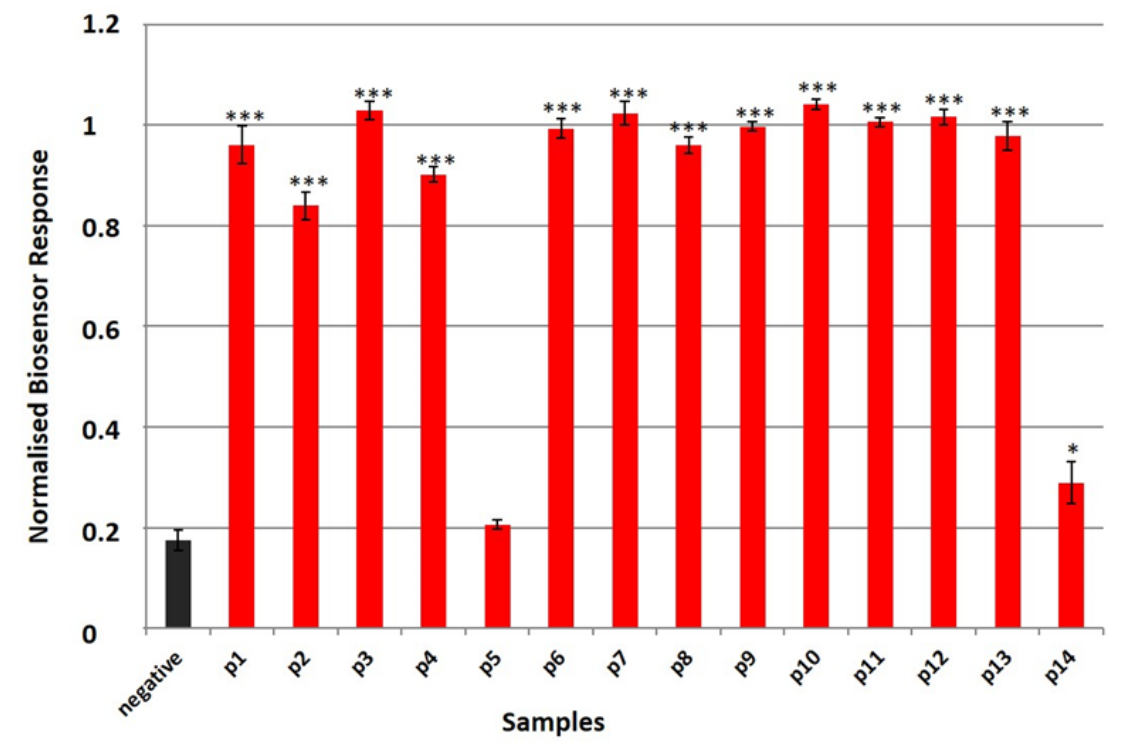

Figure 6. Normalized 3D cell biosensor's responses against clinical samples from patients $(n=14)$ and healthy donors (mean of 10 samples-black column). Results are presented after three minutes of sample-cell interaction. Results are expressed as normalized biosensor responses ([control-sample response]/control). Significant differences (Student's $T$-test) between normalized biosensor responses ${ }^{*}<0.05,{ }^{* *}<0.01,{ }^{* * *}<0.001$. 
3.3. Membrane Engineered Cells Can Be Maintained in the Hydrogel-Based Matrix for a Minimum Two Week Interval

The day after electroporation, cells were detached from the Petri dish and transferred to the hydrogel extracellular matrix. The assessment of cell proliferation started after $24 \mathrm{~h}$. Fresh medium was added every two days. Pictures of the cells were taken every 3 days. Figure 7 shows the microscopic observations of the 3D cultures after 15 days of incubation in a cell culture chamber, whereas Figure 8 depicts the graphical representation of cell viability as the percentage of live cells of the total number of cells. As can be seen, the immobilization matrix did not seem to negatively affect cell viability up to day 15 . This also coincided with the highly reproducible biosensor responses against clinical samples throughout the observation period.
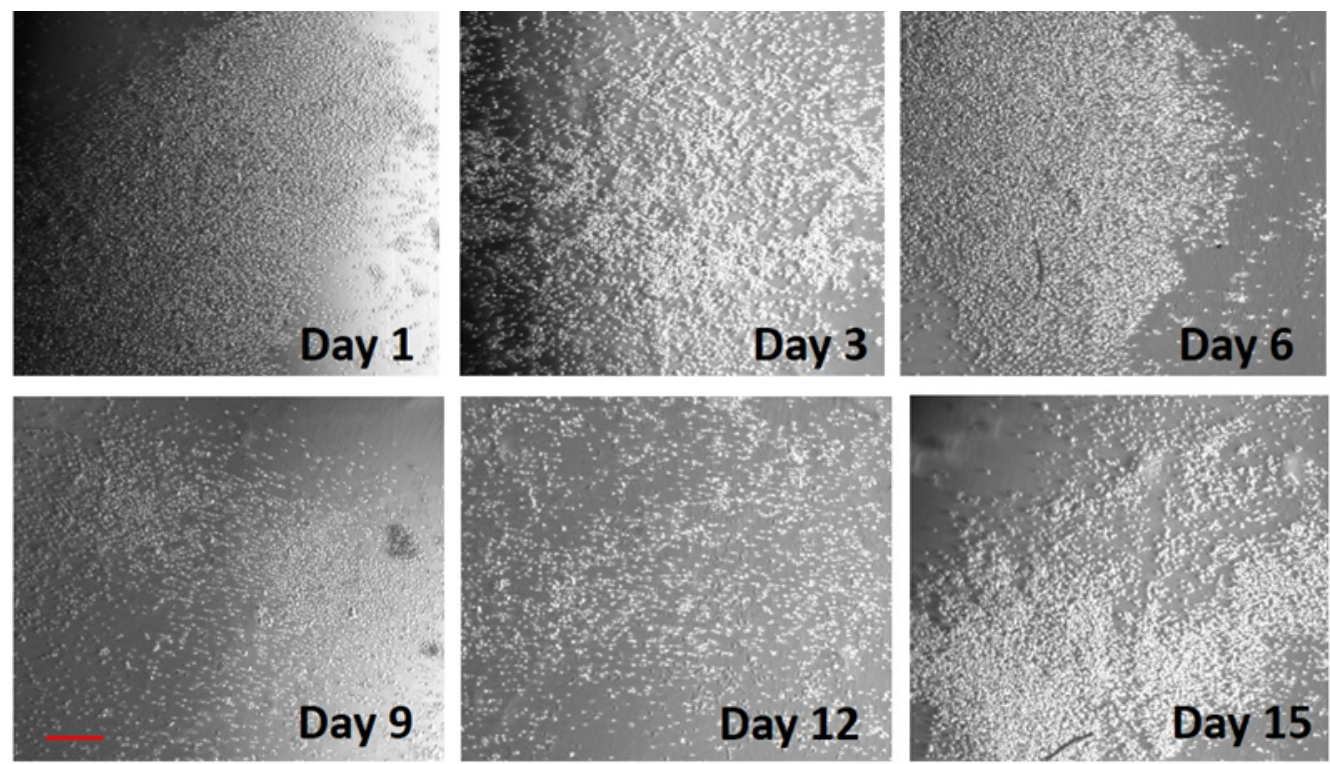

Figure 7. Panoramic view of membrane-engineered cells cultured in the hydrogel matrix after incubation for 15 days. Pictures were taken every 3 days. Scale bars $=50 \mu \mathrm{m}$.

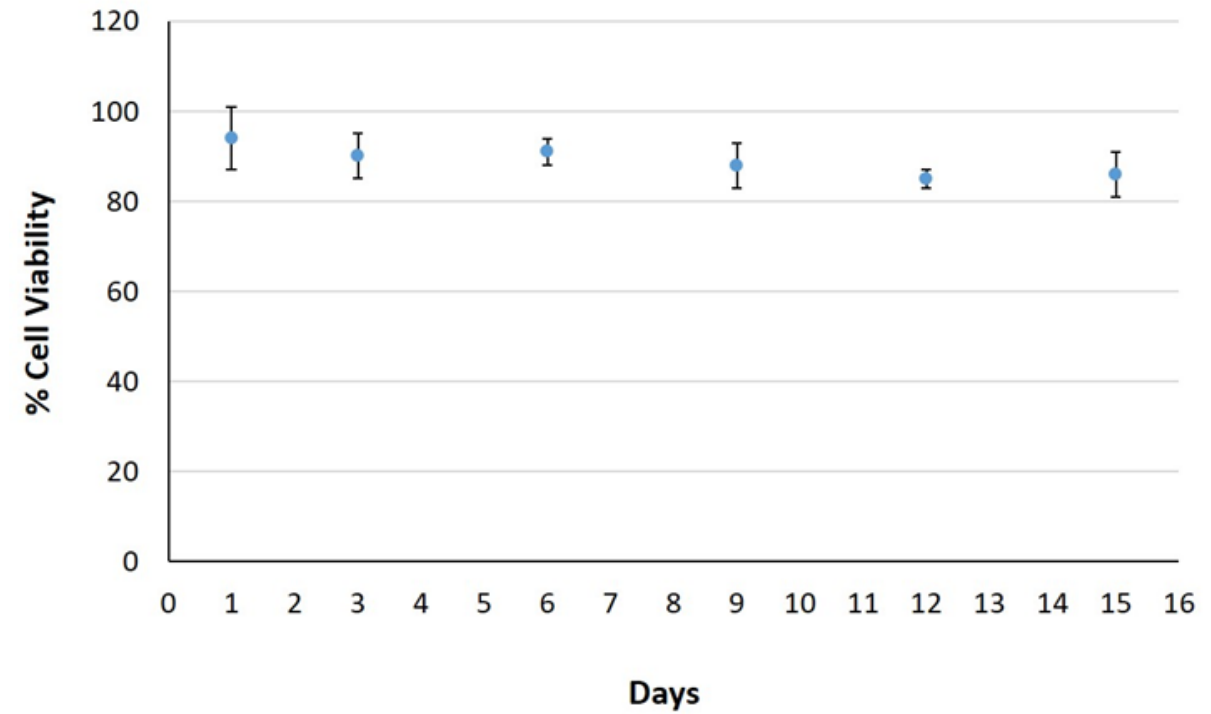

Figure 8. The graph depicts the percentage of cell viability during time. 


\section{Discussion}

Due to the brief history of the COVID-19 epidemic and in spite of its global dimension, diagnostics of the disease are still evolving. RT-PCR tests on nasopharyngeal and throat swabs are considered the current golden standard for the reliable identification of positive samples, although problems related to the costs of mass application, occasional falsenegative results and lack of detection of the virus during the early phase of the infection [1] Another drawback of molecular testing is the fact that detection of viral RNA does not always equal a viable virus [7]. On the other hand, the focus of antigen tests is steadily increasing thanks to a number of clinical trials demonstrating their high level of specificity and sensitivity, and a high agreement rate with RT-PCR (depending on the viral load) at least as far as the nucleocapsid protein is concerned [3,39-41]. An additional advantage of antigen assays is their lower variability since they are independent of aberrant changes in viral load per stage of infection [42]. Furthermore, antigen-based tests are superior to SARS-CoV-2 serology because they avoid the pitfall of false-negative results due to possible weak host immune responses [43]. That said, several challenges are still associated with the achievement of a reliable testing process, for example, minimizing the variation of results between different types of samples as well as the timing of sample collection relative to the onset of the illness and the method of sample collection [44]. Antigen tests are advantageous in this respect, too, since viral RNAs are much less stable during transport and storage than proteins.

As already mentioned in the Introduction, there are very few antigen-based assays for the detection of spike SARS-CoV-2 S1 antigen that have been clinically tested so far. For example, Lee et al. [24] very recently reported the development of a lateral flow immunoassay based on the S1-binding SARS-CoV-2 receptor ACE2 with a limit of detection of $1.86 \times 10^{5}$ copies $/ \mathrm{mL}$. Their method was clinically validated on nasopharyngeal swab samples from four COVID-19 patients and four healthy subjects. The subsequent analysis showed three positive results from confirmed clinical specimens with RT-PCR analysis, while no false-positive results were recorded. Our cellular biosensor-based approach is the second example of a clinically validated method in the rapidly expanding field of technology targeting coronavirus spike proteins as a strategy for global surveillance of COVID-19 and diseases possibly related to other respiratory viruses.

One of the major challenges for the broad application of cell-based assays (CBAs) in routine analytical and diagnostic needs is their potential for practical applicability, often limited by specific requirements for the availability of custom cell cultures (as the primary consumable) and associated equipment at the site of the assay/testing process. This condition renders the wide use of cell-based biosensor principles practically impossible, especially in resource-limited environments. Overcoming the hurdle of limited cell viability by using specific cell types (e.g., fish gills) or integrating microfluidic/organ-on-chip circuits in the consumable modules of biosensing platforms is only one of the potential areas for improving the performance of advanced CBAs [45-47]. Equally important is the ability to achieve highly reproducible test results within the linear range of responses; this is not always guaranteed when using cell suspension cultures, in particular when cell densities are not kept constant or are not clearly defined. For example, a common problem for cells removed from optimal incubation conditions (e.g., $37^{\circ} \mathrm{C}, 5 \% \mathrm{CO}_{2}$ ) to be used under field conditions is their gradual loss of viability over a period of hours or days, which in turn may lead to major inconsistencies of their response to a certain analyte. Finally, handling cell cultures at the testing site demands the engagement of technically skilled operators and can be time-consuming.

In the present study, we improved our previously developed [25] and clinically validated [30] biosensor for the detection of the SARS-CoV-2 S1 spike antigen giving emphasis on the following priorities: (i) increasing the practical ease of application of the novel system in view of its potential large scale use; (ii) ensuring the derivation of reproducible, cell batch-independent test results; and (iii) reducing the duration of each assay as well as the time between subsequent assays, as an additional measure to reach a high throughput 
performance. Our major intervention to achieve these goals was the use of a cell immobilization approach. This not only enabled the vertical extension of cell viability (at least up to two weeks) (Figures 7 and 8) but also the considerable increase of ease of use and speed of each test, with the lag period between subsequent assays being reduced to just a few seconds and practically corresponding to the time required for changing the cartridge containing the electrode strip of the 3D-immobilized cells. It is also worth mentioning that the consumable cartridges were batch stored during the whole experimental period with no impact on the reproducibility of the test results. It has been previously reported that cell immobilization is one of the most favorable methods for increasing cell viability [48,49] (up to a few weeks [50]), an approach that has also been successfully applied on membrane-engineered mammalian cells [51].

Our results indicate that as concentrations of analyte increase, the signal from immunoassays increases as well; thus, the proposed biosensor can quantitatively determine the $\mathrm{S} 1$ protein to concentrations up to $20 \mathrm{pg} / \mathrm{mL}$ (especially in the case of the 3D cultures). The increase in the response should be linear in accordance with the increase of the analyte's concentration. However, as the concentration of analyte increases above a certain point, the system gets saturated and the signal begins to decline. This phenomenon is known as the hook effect [52]. In this case, a concentration-dependent linear pattern was observed after the administration of increasing concentrations of the SARS-CoV-2 spike S1 protein, in the range of $2 \mathrm{fg} / \mathrm{mL}-20 \mathrm{pg} / \mathrm{mL}$. Additionally, the responses of the cells in 3D cultures as well as in suspension, upon the addition of the $\mathrm{S} 1$ protein solution, were similar. The 3D cultured cells produced more reproducible responses for each applied concentration of S1 protein, in comparison with the respective responses of the cell suspensions.

On the performance side, the biosensor was able to successfully identify positive samples with 93\% accuracy, while no false negative samples were recorded. Our results are in accordance with a previous study with the BERA method conducted by Apostolou et al. [32]. The biosensor showed a sensitivity of $92.7 \%(102 / 110)$ against RT-PCR with clinical samples. In our case, a rather remarkable reproducibility (average RSE\%: 3.6\%) was determined, once again demonstrating the merits of the cell immobilization approach when compared to cells in suspension (average RSE\%: 6.8\%).

The selection of clinical samples was based on matching factors, such as age and sex, that are commonly used in clinical studies. This process was performed in order to improve study efficiency by generating a comparable group of negative samples selected from the same population as the positive cases [53]. As can be seen in Table S1, patients 2, $7,8,10,11$, and 12 had a positive RT-PCR test a few days prior or after specimen selection. Furthermore, patients 1, 4, 6, 9, and 11 had been positive for SARS-CoV-2 almost one month prior to the sample collection, indicating that the biosensor (with both cell culture approaches) is able to detect the disease even at very low concentrations of the virus. Even though patient 5 was initially found positive for COVID-19 at 20 February 2021, the second RT-PCR test performed at 17 March 2021, five days after specimen selection for antigen detection, was negative. The lack of viral copies might be a possible explanation for the ambiguous results of both cell-based biosensor systems used in the study (Figures 5 and 6). Moreover, the biosensor using cell suspensions as the bioelectric recognition part was not able to identify as positive for SARS-CoV-2 specimen collected from patient 14 . This result could be attributed to the biosensor's interference with the complicated medical treatment he was receiving, indicating once again the value of cell immobilization $(p<0.05)$.

Based on our current laboratory-scale protocol for manufacturing consumable cellbearing electrodes containing the cellular biorecognition material and the electrode interface, as well as our extended experience with commercial applications of membraneengineered cells, we have calculated a capacity of at least 1000 test kits each day from a small production line operated by a single person. Furthermore, immobilization of cells at a much lower density compared to the previously reported cell suspension-based approach [24] is directly associated with a drastic reduction of the consumable costs. To our best knowledge from current collaborations with national and international partners, 
consumable cartridges containing electrodes with immobilized cells can be shipped by common methods of transport to remote end-users with no loss in functionality for at least 2-3 weeks.

\section{Conclusions}

In this report, we demonstrated the clinical applicability of a practically improved and readily employable version of our previously published cell-based biosensor for the detection of COVID-19 in nasopharyngeal swabs. Since the completion of the proof-ofconcept development of the original assay, we have launched an optimization process including the expansion of the number of cell lines to be membrane-engineered with the human chimeric spike S1 antibody and by further investigating the cross-reactivity and specificity of the biosensor, in particular against the $S$ proteins of other coronaviruses. In addition, among our immediate next research goals is the development, using our methodological approach, of a biosensor for the detection of the NC antigen and its subsequent application in saliva samples together with the present S1-specific biosensor. In this way, we expect that both the sensitivity and the selectivity of the assay will be increased [9].

Supplementary Materials: The following are available online at https://www.mdpi.com/article/10 $.3390 /$ bios11070224/s1, Table S1: The timeline of patients' personal and medical history.

Author Contributions: Conceptualization, S.K.; methodology, S.K. and S.M.; formal analysis, S.K., S.M., F.P., K.H., V.T., P.B., A.M., A.K., E.K. (Elissavet Konstantellou), G.I.L., E.K. (Eleni Koniari), E.-B.T., J.P., D.I. and G.P.C.; investigation S.M., F.P. and S.K.; data curation, S.M., K.H., V.T. and A.M.; writing-original draft preparation, S.K., K.H., A.M., V.T. and S.M.; writing-review and editing, S.K.; supervision, S.K. All authors have read and agreed to the published version of the manuscript.

Funding: This research received no external funding.

Institutional Review Board Statement: The study was conducted according to the guidelines of the Declaration of Helsinki, and approved by the Ethics Committee of the Agricultural University of Athens (protocol code 35 and date of approval 10 June 2021).

Informed Consent Statement: Informed consent was obtained from all subjects involved in the study.

Data Availability Statement: The data presented in this study are available on request from the corresponding author. The data are not publicly available due to medical confidentiality and privacy.

Acknowledgments: The authors acknowledge the administrative support of Evangelos Koukounasoulis and Stavros Ousios.

Conflicts of Interest: The authors declare no conflict of interest.

\section{References}

1. Sethuraman, N.; Jeremiah, S.S.; Ryo, A. Interpreting Diagnostic Tests for SARS-CoV-2. JAMA 2020, 323, 2249-2251. [CrossRef]

2. Baharun, B.N.B.; Safuan, S. Effectiveness of antibody vs antigen based detection method and the screening approaches to combat COVID-19. J. Sustain. Sci. Manag. 2021, 16, 29-37. [CrossRef]

3. Chaimayo, C.; Kaewnaphan, B.; Tanlieng, N.; Athipanyasilp, N.; Sirijatuphat, R.; Chayakulkeeree, M.; Angkasekwinai, N.; Sutthent, R.; Puangpunngam, N.; Tharmviboonsri, T.; et al. Rapid SARS-CoV-2 antigen detection assay in comparison with real-time RT-PCR assay for laboratory diagnosis of COVID-19 in Thailand. Virol. J. 2020, 17, 177. [CrossRef]

4. Sims, M.D.; Maine, G.N.; Childers, K.L.; Podolsky, R.H.; Voss, D.R.; Berkiw-Scenna, N.; Oh, J.; Heinrich, K.E.; Keil, H.; Kennedy, R.H.; et al. COVID-19 seropositivity and asymptomatic rates in healthcare workers are associated with job function and masking Clin. Infect. Dis. 2020. [CrossRef] [PubMed]

5. Xiang, F.; Wang, X.; He, X.; Peng, Z.; Yang, B.; Zhang, J.; Zhou, Q.; Ye, H.; Ma, Y.; Li, H.; et al. Antibody Detection and Dynamic Characteristics in Patients With Coronavirus Disease 2019. Clin. Infect. Dis. 2020, 71, 1930-1934. [CrossRef]

6. Schuler, C.F.I.V.; Gherasim, C.; O'Shea, K.; Manthei, D.M.; Chen, J.; Giacherio, D.; Troost, J.P.; Baldwin, J.L.; Baker, J.R., Jr. Accurate point-of-care serology tests for COVID-19. PLoS ONE 2021, 16, e248729. [CrossRef]

7. Wölfel, R.; Corman, V.M.; Guggemos, W.; Seilmaier, M.; Zange, S.; Müller, M.A.; Niemeyer, D.; Jones, T.C.; Vollmar, P.; Rothe, C.; et al. Virological assessment of hospitalized patients with COVID-2019. Nature 2020, 581, 465-469. [CrossRef] [PubMed]

8. Sitjar, J.; Liao, J.D.; Lee, H.; Tsai, H.P.; Wang, J.R.; Liu, P.Y. Challenges of SERS technology as a non-nucleic acid or -antigen detection method for SARS-CoV-2 virus and its variants. Biosens. Bioelectron. 2021, 181. [CrossRef] [PubMed] 
9. Kucirka, L.M.; Lauer, S.A.; Laeyendecker, O.; Boon, D.; Lessler, J. Variation in False-Negative Rate of Reverse Transcriptase Polymerase Chain Reaction-Based SARS-CoV-2 Tests by Time Since Exposure. Ann. Int. Med. 2020, 173, 262-267. [CrossRef]

10. van Kasteren, P.B.; van der Veer, B.; van den Brink, S.; Wijsman, L.; de Jonge, J.; van den Brandt, A.; Molenkamp, R.; Reusken, C.; Meijer, A. Comparison of seven commercial RT-PCR diagnostic kits for COVID-19. J. Clin. Virol. 2020, 128, 104412. [CrossRef] [PubMed]

11. Serrano, M.M.; Rodríguez, D.N.; Palop, N.T.; Arenas, R.O.; Córdoba, M.M.; Mochón, M.D.O.; Cardona, C.G. Comparison of commercial lateral flow immunoassays and ELISA for SARS-CoV-2 antibody detection. J. Clin. Virol. 2020, 129, 104529. [CrossRef]

12. Van Elslande, J.; André, E.; Van Ranst, M.; Lagrou, K.; Vermeersch, P. Immunoassays for anti-SARS-CoV-2 antibodies: Recent insights. Lancet Infect. Dis. 2020, 21, e120. [CrossRef]

13. Kotsiou, O.S.; Pantazopoulos, I.; Papagiannis, D.; Fradelos, E.C.; Kanellopoulos, N.; Siachpazidou, D.; Kirgou, P.; Mouliou, D.S.; Kyritsis, A.; Kalantzis, G.; et al. Repeated Antigen-Based Rapid Diagnostic Testing for Estimating the Coronavirus Disease 2019 Prevalence from the Perspective of the Workers' Vulnerability before and during the Lockdown. Int. J. Environ. Res. Public Health 2021, 18, 1648. [CrossRef]

14. Anonymous. Antigen-detection in the diagnosis of SARS-CoV-2 infection using rapid immunoassays. WHO Int. Guid. 2020, 11, $1-9$.

15. Reno, C.; Lenzi, J.; Golinelli, D.; Gori, D.; Signorelli, C.; Kraemer, J.; Stoto, M.A.; Avitabile, E.; Landini, M.P.; Lazzarotto, T.; et al. SARS-CoV-2/COVID-19 Testing: The Tower of Babel. Acta Bio-Medica Atenei Parm. 2020, 91, e2020144. [CrossRef]

16. Matsuda, E.M.; de Campos, I.B.; de Oliveira, I.P.; Colpas, D.R.; Carmo, A.M.D.S.; Brígido, L.F.D.M. Field evaluation of COVID-19 antigen tests versus RNA based detection: Potential lower sensitivity compensated by immediate results, technical simplicity, and low cost. J. Med. Virol. 2021, 93, 4405-4410. [CrossRef] [PubMed]

17. Li, H.; Liu, S.M.; Yu, X.H.; Tang, S.L.; Tang, C.K. Coronavirus disease 2019 (COVID-19): Current status and future perspectives. Int. J. Antimicrob. Agents 2020, 55, 105951. [CrossRef] [PubMed]

18. Aiello, A.; Fard, S.N.; Petruccioli, E.; Petrone, L.; Vanini, V.; Farroni, C.; Cuzzi, G.; Navarra, A.; Gualano, G.; Mosti, S.; et al. Spike is the most recognized antigen in the whole-blood platform in both acute and convalescent COVID-19 patients. Int. J. Infect. Dis. 2021, 106, 338-347. [CrossRef]

19. Sheridan, C. Fast, portable tests come online to curb coronavirus pandemic. Nat. Biotechnol. 2020, 38, 515-518. [CrossRef] [PubMed]

20. Mboumba Bouassa, R.S.; Veyer, D.; Péré, H.; Bélec, L. Analytical performances of the point-of-care SIENNA ${ }^{\mathrm{TM}}$ COVID-19 Antigen Rapid Test for the detection of SARS-CoV-2 nucleocapsid protein in nasopharyngeal swabs: A prospective evaluation during the COVID-19 second wave in France. Int. J. Infect. Dis. 2021, 106, 8-12. [CrossRef]

21. Kirchdoerfer, R.N.; Wang, N.; Pallesen, J.; Wrapp, D.; Turner, H.L.; Cottrell, C.A.; Corbett, K.S.; Graham, B.S.; McLellan, J.S.; Ward, A.B. Stabilized coronavirus spikes are resistant to conformational changes induced by receptor recognition or proteolysis. Sci. Rep. 2018, 8, 15701. [CrossRef]

22. Song, W.; Gui, M.; Wang, X.; Xiang, Y. Cryo-EM structure of the SARS coronavirus spike glycoprotein in complex with its host cell receptor ACE2. PLoS Pathog. 2018, 14, e1007236. [CrossRef]

23. Hulswit, R.J.G.; Lang, Y.; Bakkers, M.J.G.; Li, W.; Li, Z.; Schouten, A.; Ophorst, B.; van Kuppeveld, F.J.M.; Boons, G.-J.; Bosch, B.-J.; et al. Human coronaviruses OC43 and HKU1 bind to 9-O-acetylated sialic acids via a conserved receptor-binding site in spike protein domain A. Proc. Natl. Acad. Sci. USA 2019, 116, 2681-2690. [CrossRef]

24. Lee, J.H.; Choi, M.; Jung, Y.; Lee, S.K.; Lee, C.S.; Kim, J.; Kim, J.; Kim, N.H.; Kim, B.T.; Kim, H.G. A novel rapid detection for SARS-CoV-2 spike 1 antigens using human angiotensin converting enzyme 2 (ACE2). Biosens. Bioelectron. 2021, 171, 112715. [CrossRef] [PubMed]

25. Mavrikou, S.; Moschopoulou, G.; Tsekouras, V.; Kintzios, S. Development of a Portable, Ultra-Rapid and Ultra-Sensitive CellBased Biosensor for the Direct Detection of the SARS-CoV-2 S1 Spike Protein Antigen. Sensors 2020, 20, 3121. [CrossRef] [PubMed]

26. Kokla, A.; Blouchos, P.; Livaniou, E.; Zikos, C.; Kakabakos, S.E.; Petrou, P.S.; Kintzios, S. Visualization of the membrane engineering concept: Evidence for the specific orientation of electroinserted antibodies and selective binding of target analytes. J. Mol. Recognit. 2013, 26, 627-632. [CrossRef] [PubMed]

27. Kintzios, S. Molecular Identification through Membrane Engineered Cells. EPO Patent 1974211, 26 July 2007. Eur. Pat. Appl.

28. Moschopoulou, G.; Vitsa, K.; Bem, F.; Vassilakos, N.; Perdikaris, A.; Blouhos, P.; Yialouris, C.; Frosyniotis, D.; Anthopoulos, I.; Mangana, O.; et al. Engineering of the membrane of fibroblast cells with virus-specific antibodies: A novel biosensor tool for virus detection. Biosens. Bioelectron. 2008, 24, 1033-1036. [CrossRef]

29. Kintzios, S.; Pistola, E.; Panagiotopoulos, P.; Bomsel, M.; Alexandropoulos, N.; Bem, F.; Ekonomou, G.; Biselis, J.; Levin, R. Bioelectric recognition assay (BERA). Biosens. Bioelectron. 2001, 16, 325-336. [CrossRef]

30. Kintzios, S.; Pistola, E.; Konstas, J.; Bem, F.; Matakiadis, T.; Alexandropoulos, N.; Biselis, I.; Levin, R. The application of the bioelectric recognition assay for the detection of human and plant viruses: Definition of operational parameters. Biosens. Bioelectron. 2001, 16, 467-480. [CrossRef]

31. Perdikaris, A.; Alexandropoulos, N.; Kintzios, S. Development of a Novel, Ultra-rapid Biosensor for the Qualitative Detection of Hepatitis B Virus-associated Antigens and Anti-HBV, Based on "Membrane-engineered" Fibroblast Cells with Virus-Specific Antibodies and Antigens. Sensors 2009, 9, 2176-2186. [CrossRef] 
32. Apostolou, T.; Kyritsi, M.; Vontas, A.; Loizou, K.; Hadjilouka, A.; Speletas, M.; Mouchtouri, V.; Hadjichristodoulou, C. Development and performance characteristics evaluation of a new Bioelectric Recognition Assay (BERA) method for rapid SARS-CoV-2 detection in clinical samples. J. Virol. Methods 2021, 293, 114166. [CrossRef]

33. Perdikaris, A.; Vassilakos, N.; Yiakoumettis, I.; Kektsidou, O.; Kintzios, S. Development of a portable, high throughput biosensor system for rapid plant virus detection. J. Virol. Methods 2011, 177, 94-99. [CrossRef]

34. Charoenkitamorn, K.; Tue, P.T.; Kawai, K.; Chailapakul, O.; Takamura, Y. Electrochemical Immunoassay Using Open Circuit Potential Detection Labeled by Platinum Nanoparticles. Sensors 2018, 18, 444. [CrossRef]

35. Apostolou, T.; Loizou, K.; Hadjilouka, A.; Inglezakis, A.; Kintzios, S. Newly Developed System for Acetamiprid Residue Screening in the Lettuce Samples Based on a Bioelectric Cell Biosensor. Biosensors 2020, 10, 8. [CrossRef] [PubMed]

36. Strober, W. Trypan Blue Exclusion Test of Cell Viability. Curr. Protoc. Immunol. 2015, 111, A3.B.1-A3.B.3. [CrossRef] [PubMed]

37. Kline, A.; Putnam, N.E.; Youn, J.-H.; East, A.; Das, S.; Frank, K.M.; Zelazny, A.M. Dacron swab and PBS are acceptable alternatives to flocked swab and viral transport media for SARS-CoV-2. Diagn. Microbiol. Infect. Dis. 2021, 99, 115209. [CrossRef]

38. Clerici, B.; Muscatello, A.; Bai, F.; Pavanello, D.; Orlandi, M.; Marchetti, G.C.; Castelli, V.; Casazza, G.; Costantino, G.; Podda, G.M. Sensitivity of SARS-CoV-2 Detection With Nasopharyngeal Swabs. Front. Public Health 2021, 8, 593491. [CrossRef] [PubMed]

39. Ciotti, M.; Maurici, M.; Pieri, M.; Andreoni, M.; Bernardini, S. Performance of a rapid antigen test in the diagnosis of SARS-CoV-2 infection. J. Med. Virol. 2021, 93, 2988-2991. [CrossRef] [PubMed]

40. Colavita, F.; Vairo, F.; Meschi, S.; Valli, M.B.; Lalle, E.; Castilletti, C.; Fusco, D.; Spiga, G.; Bartoletti, P.; Ursino, S.; et al. COVID-19 Rapid Antigen Test as Screening Strategy at Points of Entry: Experience in Lazio Region, Central Italy, August-October 2020. Biomolecules 2021, 11, 425. [CrossRef]

41. Gili, A.; Paggi, R.; Russo, C.; Cenci, E.; Pietrella, D.; Graziani, A.; Stracci, F.; Mencacci, A. Evaluation of Lumipulse®G SARS-CoV-2 antigen assay automated test for detecting SARS-CoV-2 nucleocapsid protein (NP) in nasopharyngeal swabs for community and population screening. Int. J. Infect. Dis. 2021, 105, 391-396. [CrossRef]

42. Hirotsu, Y.; Maejima, M.; Shibusawa, M.; Nagakubo, Y.; Hosaka, K.; Amemiya, K.; Sueki, H.; Hayakawa, M.; Mochizuki, H.; Tsutsui, T.; et al. Comparison of automated SARS-CoV-2 antigen test for COVID-19 infection with quantitative RT-PCR using 313 nasopharyngeal swabs, including from seven serially followed patients. Int. J. Infect. Dis 2020, 99, 397-402. [CrossRef]

43. Bélec, L.; Péré, H.; Mboumba Bouassa, R.S.; Veyer, D.; Jenabian, M.A. Potential pitfalls of routine SARS-CoV-2 serology for mass screening. J. Med. Virol. 2020, 92, 2345. [CrossRef] [PubMed]

44. Wang, W.; Xu, Y.; Gao, R.; Lu, R.; Han, K.; Wu, G.; Tan, W. Detection of SARS-CoV-2 in Different Types of Clinical Specimens. JAMA 2020, 323, 1843-1844. [CrossRef]

45. Schopow, N.; Kallendrusch, S.; Gong, S.; Rapp, F.; Körfer, J.; Gericke, M.; Spindler, N.; Josten, C.; Langer, S.; Bechmann, I. Examination of ex-vivo viability of human adipose tissue slice culture. PLoS ONE 2020, 15, e0233152. [CrossRef] [PubMed]

46. Banerjee, P.; Kintzios, S.; Prabhakarpandian, B. Biotoxin detection using cell-based sensors. Toxins 2013, 5, 2366-2383. [CrossRef]

47. Kintzios, S.E. Cell-based biosensors in clinical chemistry. Mini Rev. Med. Chem. 2007, 7, 1019-1026. [CrossRef]

48. Hasturk, O.; Kaplan, D.L. Cell armor for protection against environmental stress: Advances, challenges and applications in microand nanoencapsulation of mammalian cells. Acta Biomater. 2019, 95, 3-31. [CrossRef] [PubMed]

49. Sablatura, L.K.; Bircsak, K.M.; Shepherd, P.; Queiroz, K.; Farach-Carson, M.C.; Constantinou, P.E.; Saleh, A.; Navone, N.; Harrington, D.A. Enhanced Viability for Ex vivo 3D Hydrogel Cultures of Patient-Derived Xenografts in a Perfused Microfluidic Platform. J. Vis. Exp. 2020, 10, e60872. [CrossRef]

50. Kintzios, S.; Yiakoumetis, I.; Moschopoulou, G.; Mangana, O.; Nomikou, K.; Simonian, A. Differential effect of the shape of calcium alginate matrices on the physiology of immobilized neuroblastoma N2a and Vero cells: A comparative study. Biosens. Bioelectron. 2007, 23, 543-548. [CrossRef] [PubMed]

51. Katsanakis, N.; Katsivelis, A.; Kintzios, S. Immobilization of electroporated cells for fabrication of cellular biosensors: Physiological effects of the shape of calcium alginate matrices and foetal calf serum. Sensors 2009, 9, 378-385. [CrossRef] [PubMed]

52. Namburi, R.; Kancherla, V.; Ponnala, A. High-dose hook effect. J. NTR Univ. Health Sci. 2014, 3, 5-7. [CrossRef]

53. Pearce, N. Analysis of matched case-control studies. BMJ 2016, 352, i969. [CrossRef] [PubMed] 